\title{
The effect of misoprostol on intraoperative blood loss after myomectomy
}

\section{Mansoureh Vahdat ${ }^{1}$, Maryam Kashanian ${ }^{2}$, Sara Asadollah $^{1}$, Payman Yazdkhasti ${ }^{3}$, Nasrin Nikravan ${ }^{4}$}

\author{
${ }^{1}$ Department of Obstetrics and Gynecology, Rasool-e-Akram Hospital, Iran University of Medical Sciences, Tehran, \\ Iran \\ ${ }^{2}$ Department of Obstetrics and Gynecology, Shahid Akbar Abadi Hospital, Iran University of Medical Sciences, \\ Tehran, Iran \\ ${ }^{3}$ Department of Anesthesiology, Rasool-e-Akram Hospital, Iran University of Medical Sciences, Tehran, Iran \\ ${ }^{4}$ Medical Student, Rasool-e-Akram Hospital, Iran University of Medical Sciences, Tehran, Iran
}

Received: 08 April 2015

Accepted: 09 May 2015

\author{
*Correspondence: \\ Dr. Sara Asadollah, \\ E-mail: sara_asadolla@yahoo.com
}

Copyright: (C) the author(s), publisher and licensee Medip Academy. This is an open-access article distributed under the terms of the Creative Commons Attribution Non-Commercial License, which permits unrestricted non-commercial use, distribution, and reproduction in any medium, provided the original work is properly cited.

\begin{abstract}
Background: Uterine myomas are common benign tumors in the reproductive period. Bleeding during myomectomy is one of the major complications. We designed a randomized clinical trial to investigate the effectiveness of misoprostol on reducing Intraoperative Blood Loss (IBL) after myomectomy.

Methods: Sixty four patients undergoing abdominal myomectomy were randomized into misoprostol group ( $\mathrm{n}=32$ ) that were given 200 micrograms sublingual misoprostol 0.5 hour before the operation and control group $(n=32)$ that were given placebo. Hemoglobin $(\mathrm{Hb})$ was recorded preoperative, $6 \mathrm{~h}$ and $24 \mathrm{~h}$ after surgery. Data were analyzed by SPSS software (V.20).

Results: Mean of age, body mass index and baseline $\mathrm{Hb}$ were not statistically significant between the groups however $\mathrm{Hb}$ in $6 \mathrm{~h}$ after operation were significantly higher in misoprostol group but not significant after $24 \mathrm{~h}$ ( $\mathrm{Hb} 6 \mathrm{~h}: 9.8 \pm 0.8$ vs. $9.1 \pm 0.9, \mathrm{P}=0.003$ and $\mathrm{Hb} 24 \mathrm{~h}: 10.50 \pm 0.56$ vs. $10.24 \pm 0.58, \mathrm{P}=0.066)$. No difference was observed in terms of anemia and need for blood transfusion after operation among the groups.

Conclusions: Preoperative use of sublingual misoprostol is effective in reducing IBL for women undergoing myomectomies in short time (after $6 \mathrm{~h}$ ). Further studies should be performed to investigate the effectiveness of preoperative misoprostol with various routes and doses in other post-operative time on reducing IBL in abdominal myomectomy.
\end{abstract}

Keywords: Misoprostol, Myomectomy, Intraoperative blood loss

\section{INTRODUCTION}

Uterine myomas are common benign tumors in the reproductive period that are composed of smooth muscle cells and variable amounts of fibrous connective tissue. ${ }^{1}$

The standard therapy for leiomyoma is hysterectomy in women who have completed childbearing period however myomectomy, the surgical removal of myomas, is the treatment of choice during the reproductive ages. ${ }^{2}$

Bleeding during myomectomy is one of the major complications which can result in significant morbidity and mortality. Despite advances in reducing the excessive hemorrhage during the procedure, it still remains a major challenge for gynecologic surgeons. ${ }^{3}$ 
Several interventions have been developed to control bleeding during this operation such as dissection and embolization of uterine artery, use of mechanical and hormonal tourniquets, use of uterotonic medications such as oxytocin, ergometrine, misoprostol. ${ }^{4-7}$

Misoprostol, a prostaglandin E1 analogue, reduces uterine blood flow by causing uterine contractions and subsequently reduces bleeding during myomectomy.,

There is always controversial for choosing the best method with minimal adverse effects and effective results among gynecologists. Few studies have been done on the beneficial effects of misoprostol. According to the high incidence of myoma and the need to control IBL, this study was designed to investigate the effectiveness of misoprostol in reducing bleeding during myomectomy.

\section{METHODS}

This double-blind randomized clinical trial was conducted on patients admitted for myomectomy in Gynecology ward at Rasool-e-Akram hospital from August 2013 to October 2014. The registration number in www.irct.ir is IRCT2014071414621N1. Inclusion criteria were over 18 years' old women undergoing myomectomies due to uterine myomas with mean size 8 centimeters in sonography report.

Patients with history of pelvic infection or sepsis, known hepatic disease, active asthma, severe hypertension, known allergy to prostaglandins, history of pelvic or ovarian endometriosis, history of bleeding disorders, use anticoagulant medications or NSAIDs and recent received packed cell were excluded. The examiner was gynecologic and obstetric assistant that take history and physical examination from patients and give the medication (misoprostol) to the patient before the operation. After explaining the study and obtaining informed consent, the patients were enrolled if they have inclusion criteria. The patients were randomly assigned into one of the four blocks categories (aabb, abab, baba) to receive misoprostol or placebo. Patients and examiner were unaware of the treatment received. Finally sixty four individuals undergoing abdominal myomectomy were randomized using block randomization into misoprostol group $(n=32)$ that were given 200 micrograms sublingual misoprostol (CYTOTEC $200 \mu \mathrm{g}$, Pfizer Factory) 30 minutes before the start of surgery and control group $(n=32)$ that were given placebo. Myomectomies were performed by the same team and patients were controlled hemodynamically during and after operation. Data were registered in collection forms including demographic characteristics, size and number of myoma and size of uterus based on sonography report, duration of operation, need for blood transfusion and hysterectomy, number of anemia, preoperative and postoperative $\mathrm{Hb}$ in 6 hours and 24 hours after surgery $(\mathrm{gm} / \mathrm{dl})$.

All analyses were performed using SPSS for Windows (version 20, Chicago, Illinois, USA). Numerical variables were reported as mean \pm Standard Deviation (SD). We used independent-t-test and Chi-square (Fisher's exact test) to compare quantitative and qualitative variables, respectively. $\mathrm{P}$ value $<0.05$ was considered statistically significant.

\section{RESULTS}

Basic characteristics of patients were described in Table 1. Mean of age, Body Mass Index (BMI), size of myoma and uterus, number of myoma and duration of surgery were not statistically different between the groups $(\mathrm{P}>0.05)$.

Table 1: Basic characteristics of patients.

\begin{tabular}{|llll|}
\hline & Misoprostol group & Control group & P value \\
\hline Age & $35.75 \pm 5.45$ & $35.69 \pm 6.75$ & 0.96 \\
\hline BMI & $28.37 \pm 2.99$ & $28.64 \pm 3.14$ & 0.72 \\
\hline Size of myoma (mean total size, cm) & $7.76 \pm 1.84$ & $7.25 \pm 1.92$ & 0.27 \\
\hline Size of uterus (cm) & $10.68 \pm 2.24$ & $10.06 \pm 2.06$ & 0.25 \\
\hline Number of myoma (mean number) & $2.75 \pm 0.71$ & $2.59 \pm 0.71$ & 0.38 \\
\hline Duration of surgery (min) & $78.28 \pm 17.94$ & $82.34 \pm 21.84$ & 0.41 \\
\hline
\end{tabular}

The main outcome measures were need for blood transfusion during surgery and reduction of post operation $\mathrm{Hb}$. The comparison of $\mathrm{Hb}$ before and after the operation and need to transfusion and hysterectomy between the groups was shown in Table 2.
Baseline $\mathrm{Hb}$ was not statistically different between the groups however $\mathrm{Hb}$ after $6 \mathrm{~h}$ of operation were significantly higher in misoprostol group. (Hb $6 \mathrm{~h}$ : $9.8 \pm$ 0.8 vs. $9.1 \pm 0.9, \mathrm{P}=0.003)$ but $\mathrm{Hb}$ after $24 \mathrm{~h}$ operation was not statistically different between the groups ( $\mathrm{Hb} 24$ h: $10.50 \pm 0.56$ vs. $10.24 \pm 0.58, \mathrm{P}=0.066)$. 
No difference was observed in terms of anemia, need to blood transfusion and hysterectomy after operation

among the groups $(\mathrm{P}>0.05)$.

Table 2: The comparison of preoperative and postoperative values between the misoprostol and control group.

\begin{tabular}{|llll|}
\hline Preoperative $\mathrm{Hb}$ & Misoprostol group & Control group & P value \\
\hline Hb 6 h post op & $10.59 \pm 1.11$ & $10.11 \pm 1.27$ & 0.11 \\
\hline Anemia & $9.80 \pm 0.88$ & $9.10 \pm 0.91$ & 0.003 \\
\hline Need to transfusion & $5(12(37.5 \%)$ & $15(46.9 \%)$ & 0.44 \\
\hline Need to hysterectomy & $1(3.1 \%)$ & $8(25 \%)$ & 0.065 \\
\hline
\end{tabular}

\section{DISCUSSION}

Concerns of complications related to myomectomy such as bleeding leads to perform studies in this regard and use several interventions to control IBL. ${ }^{3}$ Therefore, several clinical trials studied the effect of different medications on blood loss during myomectomy for uterine myoma. ${ }^{7,8}$ One of the drugs being researched is misoprostol, a synthetic analogue of prostaglandin E1 that has been commonly used in obstetrics and gynecologic practice. ${ }^{8}$ However little is known about its efficacy in gynecologic surgery such as myoma. In this study sixty four patients undergoing abdominal myomectomy were evaluated. Mean of $\mathrm{Hb}$ in $6 \mathrm{~h}$ after operation were significantly higher in misoprostol group which represents sublingual misoprostol reduced bleeding but $\mathrm{Hb}$ in $24 \mathrm{~h}$ after operation were similar in two groups.

Misoprostol can be administered through various routes including oral, vaginal, rectal and sublingual. ${ }^{10,11} \mathrm{We}$ compared the effect of sublingual misoprostol on reducing IBL with placebo group however recent studies used vaginal or rectal routes. ${ }^{9,12}$

The higher peak concentration of misoprostol is achieved by sublingual route rather than oral or vaginal administration due to rapid absorption from sublingual mucosa, therefore this kind of administration route is beneficial in clinical practices that require a rapid onset of action such as intraoperative bleeding during gynecological surgeries. ${ }^{13}$

Celik and Sapmaz $^{8}$ showed that use of vaginal misoprostol (a single dose of $400 \mathrm{mcg}$ ) significantly reduced blood loss, duration of surgery and the need for blood transfusion postoperatively in myomectomy.

Naib et al. in other clinical trial that was conducted in Pakistan from 2010 to 2012, found that preoperative use of $400 \mathrm{mcg}$ misoprostol via rectal route significantly reduced IBL and need for blood transfusion. ${ }^{12}$

Mechanism of action of misoprostol is increasing myometrial contractions in uterus that cause vessels contractions and subsequently reducing blood flow in uterine arteries and also it has been shown to increase the uterine artery resistance and reduce the blood flow to the myomas. $^{8,9}$

Misoprostol has been shown to be effective in the treatment and prevention of postpartum hemorrhage but the effect is not more than conventional uterotonics (oxytocin and ergotamine), however it is an option when other uterotonic agents are fail or not available. ${ }^{14}$

In this study no differences have been found in $\mathrm{Hb} 24 \mathrm{~h}$, terms of anemia and need for blood transfusion after operation among the groups. There is insufficient data about the effect of misoprostol on the need for blood transfusion, hospital stay duration and postoperative morbidity.

Our study showed that preoperative use of sublingual misoprostol is effective in reducing IBL in short time (after $6 \mathrm{~h}$ ) but not very useful to control long time IBL for women undergoing myomectomies. Further studies should be performed to investigate the effectiveness of preoperative misoprostol with various routes and doses on reducing IBL in other time of post operation abdominal myomectomy.

Funding: No funding sources Conflict of interest: None declared

Ethical approval: The study was approved by the institutional ethics committee (IRCT2014071414621N1)

\section{REFERENCES}

1. Buttram VC Jr, Reiter RC. Uterine leiomyomata: etiology, symptomatology, and management. Fertil Steril. 1981 Oct;36(4):433-45.

2. Parker WH. Uterine myomas: management. Fertil Steril. 2007 Aug;88(2):255-71.

3. LaMorte AI, Lalwani S, Diamond MP. Morbidity associated with abdominal myomectomy. Obstet Gynecol. 1993 Dec;82(6):897-900.

4. Lethaby A, Vollenhoven B, Sowter M. Pre-operative GnRH analogue therapy before hysterectomy or myomectomy for uterine fibroids. Cochrane Database Syst Rev. 2001;(2):CD000547.

5. Liu W, Tzeng C, Yi-Jen C, Wang P. Combining the uterine depletion procedure and myomectomy may 
be useful for treating symptomatic fibroids. Fertil Steril. 2004 Jul;82(1):205-10.

6. Ngeh N, Belli A, Morgan R, Manyonda I. Premyomectomy uterine embolization minimizes operative blood loss. BJOG. 2004 Oct;111(10):113940.

7. Chang FW, Yu MH, Ku CH, Chen $\mathrm{CH}, \mathrm{Wu}$ GJ, Liu JY. Effect of uterotonics on intra-operative blood loss during laparoscopy-assisted vaginal hysterectomy: a randomised controlled trial. BJOG. 2006 Jan;113(1):47-52.

8. Celik H, Sapnaz E. Use of a single preoperative dose misoprostol is efficacious for patients who undergo abdominal myomectomy. Fertil Steril. 2003 May;79(5):1207-10.

9. Wray S. Uterine contraction and physiological mechanisms of modulation. Am J Physiol. 1993 Jan;264(1 Pt 1):1-18.

10. Khan RU, El-Refaey H, Sharma S, Sooranna D, Stafford M. Oral, rectal, and vaginal pharmacokinetics of misoprostol. Obstet Gynecol. 2004 May;103(5 Pt 1):866-70.

11. Tang OS, Schweer H, Seyberth HW, Lee SW, Ho PC. Pharmacokinetics of different routes of administration of misoprostol. Hum Reprod. 2002 Feb;17(2):332-6.

12. Naib JM, Naveed P, Fatima S. Pre-operative use of misoprostol in major gynaecological surgeries. $\mathrm{J}$ Med Sci. 2013;21(4):171-3.

13. Tang OS, Gemzell-Danielsson K, Ho PC. Misoprostol: pharmacokinetic profiles, effects on the uterus and side-effects. Int J Gynaecol Obstet. 2007 Dec;99(2):160-7.

14. Allen R, M O'Brien B. Uses of misoprostol in obstetrics and gynecology. Rev Obstet Gynecol. 2009;2(3):159-68.

DOI: 10.18203/2320-1770.ijrcog20150090

Cite this article as: Vahdat M, Kashanian M, Asadollah S, Yazdkhasti P, Nikravan N. The effect of misoprostol on intraoperative blood loss after myomectomy. Int J Reprod Contracept Obstet Gynecol 2015;4:776-9. 